\title{
Comparative Study of Molecularly Imprinted Polymer and Magnetic Molecular Imprinted Nanoparticles as Recognition Sites for the Potentiometric Determination of Gemifloxacin Mesylate
}

\author{
Nehad A. Abdallah ${ }^{1,2, *}$, Heba F. Ibhrahim ${ }^{2}$, Nayira H. Hegabe ${ }^{2}$ \\ ${ }^{1}$ Pharmacognosy and Pharmaceutical Chemistry Department, Faculty of Pharmacy, Taibah University, \\ Al-Madinah Al-Mounawarah 41477, KSA \\ ${ }^{2}$ Experiments and Advanced Pharmaceutical Research Unit, Faculty of Pharmacy, Ain Shams \\ University, Cairo 1156, Egypt \\ *E-mail: nehad.amin@gmail.com
}

doi: $10.20964 / 2017.11 .74$

Received: 2 August 2017 / Accepted: 17 September 2017 / Published: 12 October 2017

Two nanoparticles based potentiometric sensors were fabricated for the selective determination of gemifloxacin mesylate. The first sensor was based on the formation of molecularly imprinted polymer nanoparticles using methacrylic acid as a functional monomer, trimethylolpropane trimethacrylate as a crosslinker and azobisisobutyronitrile as the initiator. The second sensor was based on the use of $\mathrm{Fe}_{3} \mathrm{O}_{4}$ magnetic nanoparticles as core shells for the molecularly imprinted polymer. The developed sensors showed high selectivity, stability and sensitivity with wide concentration ranges of $1 \times 10^{-3}-1 \times 10^{-8} \mathrm{~mol}$ $\mathrm{L}^{-1}$ and $1 \times 10^{-3}-1 \times 10^{-10} \mathrm{~mol} \mathrm{~L}^{-1}$ for sensors 1 and 2 , respectively. They were efficiently applied for the determination of gemifloxacin mesylate in bulk, pharmaceutical tablets and spiked human plasma.

Keywords: Gemifloxacin; molecularly imprinted; magnetic nanoparticles; carbon paste electrode

\section{$\underline{\text { FULL TEXT }}$}

(C) 2017 The Authors. Published by ESG (www.electrochemsci.org). This article is an open access article distributed under the terms and conditions of the Creative Commons Attribution license (http://creativecommons.org/licenses/by/4.0/). 